\title{
Correction to: Venous Circulation: A Few Challenging Concepts in Goal-Directed Hemodynamic Therapy (GDHT)
}

\author{
Simon Gelman
}

\section{Correction to: E. Farag et al. (eds.), Perioperative Fluid Management, https://doi.org/10.1007/978-3-030-48374-6_16}

The original version of this chapter was inadvertently published with three Authors instead of one Author. The chapter and book front matter has been corrected to one Author, Dr. Simon Gelman, the sole author of the chapter. 